\title{
B-cell lymphoma 2 and $\beta$-catenin expression in colorectal cancer and their prognostic role following surgery
}

\author{
MANUELA BALZI ${ }^{1}$, MARIA NOVELLA RINGRESSI ${ }^{2}$, PAOLA FARAONI $^{1}$, CATHERINE BOOTH $^{3}$, \\ ANTONIO TADDEI $^{2}$, LUCA BONI ${ }^{4}$ and PAOLO BECHI ${ }^{2}$ \\ ${ }^{1}$ Department of Biomedical, Experimental and Clinical Sciences, University of Florence, Florence 50139; \\ ${ }^{2}$ Department of Surgery and Translational Medicine, University of Florence, Florence 50134, Italy; \\ ${ }^{3}$ Epistem Limited, Incubator Building, Manchester M13 9XX, United Kingdom; \\ ${ }^{4}$ Clinical Trials Coordinating Center, Careggi Hospital and Tumour Institute of Tuscany, Florence 50134, Italy
}

Received March 3, 2014; Accepted December 12, 2014

DOI: $10.3892 / \mathrm{mmr} .2015 .3385$

\begin{abstract}
The prognosis of colorectal cancer depends on the stage of the disease. However, even within the same stage there may be different outcomes in terms of recurrence and survival. Therefore, it is clear that as well as pathological stage, novel biomarkers that are capable of improving risk stratification and therapeutic decision-making are required. The present study aimed to evaluate the potential roles of two previously proposed biomarkers of tumour status: B-cell lymphoma 2 (Bcl-2) and $\beta$-catenin. A total of 412 patients undergoing surgery for primary colorectal cancer were studied. Tumour specimens of the patients were collected, fixed and processed for immunohistochemical detection of $\mathrm{Bcl}-2$ and $\beta$-catenin. The data were then analyzed in relation to disease-free survival and overall survival. Pathological stage was the only variable that was significantly correlated with both disease-free and overall survival. The expression levels of neither Bcl-2 nor $\beta$-catenin were able to accurately predict prognosis. However, there was a clear association between nuclear $\beta$-catenin expression levels and disease-free survival in the three tumour stages. There was an increased hazard ratio in stage I and II nuclear $\beta$-catenin positive tumours, whereas there was a marked decrease in risk in stage III positive tumours. A similar effect was also observed with regards to overall survival, however this finding was not significant. The results of the present study suggest that conventional pathological tumour staging is the only accurate prognostic method. Neither Bcl-2 or $\beta$-catenin were shown to be useful biomarkers for the prognosis of colorectal cancer. However, the heterogeneous behaviour of nuclear $\beta$-catenin expression in the various tumour stages may indicate a possible
\end{abstract}

Correspondence to: Dr Manuela Balzi, Department of Biomedical, Experimental and Clinical Sciences, University of Florence, 6 Viale Pieraccini, Florence 50139, Italy

E-mail: manuela.balzi@unifi.it

Key words: colorectal cancer, immunohistochemistry, B-cell lymphoma $2, \beta$-catenin, prognosis role in predicting the response of patients to chemotherapy. Therefore, nuclear $\beta$-catenin expression may be a biomarker for the prediction of improved responses to chemotherapy.

\section{Introduction}

Colorectal cancer (CRC) is a significant health problem worldwide. It is the most common newly diagnosed cancer and the second most common cause of cancer-associated mortality in Europe, accounting for 436,000 cases and 212,000 deaths in $2008(1,2)$.

The prognosis of CRC markedly differs between the early and late stages of the disease. In stage I or II cancers, the postoperative five-year recurrence rate is $<30 \%$, whereas in stage III cancer it is $60 \%(3,4)$. However, it is well-known that patients with the same stage of disease may have substantially different outcomes. Specifically, a minority of patients with stage II CRC have a poor outcome. However, the identification of this subset of patients remains unpredictable using the traditional staging system $(5,6)$. Therefore, the identification of novel predictive factors that are capable of improving risk stratification and therapeutic decision-making is required. A deeper insight into the basic genetic mechanisms that underlie the development of CRC may be beneficial for the identification of novel biomarkers. Noteworthy progress has been achieved in this area since 1990, when Fearon and Vogelstein (7) reported their multistep genetic model of colorectal tumourigenesis. According to this model, a series of genetic alterations, such as the activation of certain oncogenes and the inactivation of particular tumour suppressor genes, are responsible for the development of CRC. Two of the genes implicated in this process are B-cell lymphoma $2(\mathrm{Bcl}-2)$ and $\beta$-catenin.

Programmed cell death prevents the expansion of damaged cells, and may be induced by various signals, including irreparable DNA damage. Bcl-2 has a role in the prevention of apoptosis. Therefore, its overexpression may promote the survival of damaged cells (8). This may lead to the continued division of mutated cells and, ultimately, to carcinogenesis.

The Wnt/ $/$-catenin signaling pathway has an important role in embryogenesis and tumorigenesis. The majority of cases of sporadic CRC and familial adenomatous polyposis exhibit 
a mutated adenomatous polyposis coli (APC) gene (9). The non-mutated APC protein downregulates the Wnt signaling pathway by binding to $\beta$-catenin and axin. However, the majority of mutated APC proteins in colorectal tumours fail to inhibit Wnt signaling, leading to over-proliferation of tumour cells (9). Furthermore, stabilized $\beta$-catenin translocates to the nucleus where it acts as a transactivation factor that promotes tumour growth $(10,11)$.

The aim of the present study was to investigate whether overexpression of Bcl-2 and/or nuclear accumulation of $\beta$-catenin represent independent prognostic factors in non-advanced operable CRC. The present study also aimed to determine the association between Bcl-2 and $\beta$-catenin, and well-established clinicopathological risk stratification parameters.

\section{Materials and methods}

Patients. Patients with CRC were prospectively enrolled in the present study between June 1993 and September 2010. All patients undergoing curative surgical resection for primary CRC in the $2^{\text {nd }}$ Urgency and General Surgery Unit (Careggi University Hospital, Florence, Italy) were considered eligible for the study. The exclusion criteria were as follows: Age $>85$ years, preoperative radiochemotherapy, distant metastases at diagnosis, hereditary non-polyposis colorectal cancer or familial adenomatous polyposis, or a personal history of other types of tumour. Patients in whom it was not possible to collect adequate tissue for biological determinations, or who did not survive past 30 days of surgery were also excluded.

Full informed consent was obtained from all of the patients following a thorough explanation of treatment options and the aims of the study.

All patients underwent standard surgery. A right hemicolectomy consisted of dividing the ileocolic and right colic vessels on the superior mesenteric axis, and a left hemicolectomy with anterior rectal resection consisted of dividing the inferior mesenteric artery at its origin, following identification of the para-aortic left nervous trunk. Cancer staging was assessed according to the American Joint Committee on Cancer/Union for International Cancer Control Tumour Node Metastasis classification (12).

Tissue specimens and immunohistochemistry. In addition to the routine procedures for histopathological diagnosis, specimens from the colorectal adenocarcinoma and from normal mucosa (at a $10 \mathrm{~cm}$ distance from the tumour) were collected from the patients immediately following surgery. The specimens were then formalin-fixed (37\% formalin; Sigma-Aldrich, St. Louis, MO, USA) and paraffin blocks (Shandon; Thermo Fisher Scientific, Waltham, MA, USA) were prepared. The tissue specimens were then cut into $4-\mu \mathrm{m}$ sections and mounted on glass slides coated with 3-aminopropyltriethoxysilane (Sigma-Aldrich, St. Louis, MO, USA), dewaxed in xylene and rehydrated with graded alcohols.

Prior to incubation with the primary antibodies, the sections were immersed in tris/EDTA buffer ( $\mathrm{pH}=9.0$; Dako, Glostrup, Denmark) and heated in a water bath $\left(96^{\circ} \mathrm{C}\right)$ for $20 \mathrm{~min}$. Following antigen retrieval, where the slides were immersed in buffer at pH 9.0 (Dako Cytomation) and incubated at $96^{\circ} \mathrm{C}$ for $20 \mathrm{~min}$, the samples were allowed to cool at room temperature and washed with phosphate-buffered saline (PBS). Endogenous peroxidase was then blocked using peroxidase-blocking reagent (Dako) for $5 \mathrm{~min}$, followed by three washes with PBS.

Mouse anti-Bcl-2 monoclonal antibody (clone 124, dilution 1:50; M0887; Dako), and mouse monoclonal anti- $\beta$-catenin (clone $\beta$-catenin-1, dilution 1:200; M3539; Dako), were applied to the specimens for $30 \mathrm{~min}$ at room temperature, in a humidified chamber. The specimens were subsequently incubated with a secondary labelled polymer (Envision System Labelled Polymer-Horseradish Peroxidase anti-mouse; Dako) for $30 \mathrm{~min}$ at room temperature, and washed with PBS three times for 3 min. Liquid 3-3'diaminobenzidine (Dako) plus substrate was then added for 5 min. Following further washing with PBS, the sections were lightly counter-stained with hematoxylin and examined with a Leitz Laborlux binocular microscope (magnification, x25/0.5; Leica Microsystems GmbH, Wetzlar, Germany). Omission of the primary antibody acted as a negative control. Immunoreactivity for Bcl-2 was evaluated according to the percentage of tumour cells with positive cytoplasmic staining. A cut-off value of $5 \%$ positive tumour cells was used to discriminate $\mathrm{Bcl}-2$ negative from $\mathrm{Bcl}-2$ positive cases. Infiltrating lymphocytes were classed as an internal positive control for immunoreactivity. Membranous $(\beta-\mathrm{M})$, cytoplasmic $(\beta-\mathrm{C})$ and nuclear $(\beta-\mathrm{N})$ staining for $\beta$-catenin were each evaluated separately. The same cut-off value of $5 \%$ positive tumour cells was used to discriminate negative from positive cases, with regard to $\beta$-catenin. $\mathrm{Bcl}-2$ and $\beta$-catenin evaluations were performed independently by two authors of the present study (Dr Manuela Balzi and Dr Paola Faraoni), who were blinded to the pathological findings.

Statistical analysis. The distribution of the patients in the present study is reported with respect to their demographic, clinical and biological characteristics, which are summarized as frequencies or percentages. The presence of an association between the demographic, clinical and biological characteristics was evaluated using a $\chi^{2}$ test for heterogeneity, and Fisher's exact test when appropriate. All of the variables were investigated in terms of their impact on the duration of disease-free survival (DFS), and overall survival (OS). DFS was defined as the interval between surgical intervention and disease recurrence, or death from any cause, depending on which occurred first. OS was defined as the time between intervention and end-of-life, regardless of the cause. The observation time of the patients who had not relapsed and were alive at the final follow-up visit was censored. Median follow-up time and interquartile range (IQR) were estimated according to the Kaplan-Meier inverse method, as previously described (13). In the univariate analysis, estimates of DFS and OS were calculated according to the Kaplan-Meier product-limit method. Comparisons of the estimated survival curves were performed by means of a log-rank test. Hazard ratios (HR) and appropriate $95 \%$ confidence intervals (CI) were also calculated by means of the Cox proportional hazard model. A multivariate Cox regression model was fitted to evaluate the independent effect of each factor on both DFS and OS. Beginning with a full model, including gender, age at diagnosis, tumour site, clinical stage, histology, Bcl-2, $\beta-\mathrm{M}$, $\beta-\mathrm{N}, \beta-\mathrm{C}$ and adjuvant chemotherapy, variables which did not 
Table I. Characteristics of the patients with CRC included and not included in the statistical analyses of the present study.

\begin{tabular}{|c|c|c|c|c|c|}
\hline \multirow[b]{2}{*}{ Variable } & \multicolumn{2}{|c|}{$\begin{array}{l}\text { Included } \\
(\mathrm{n}=321)\end{array}$} & \multicolumn{2}{|c|}{$\begin{array}{l}\text { Not included } \\
\quad(\mathrm{n}=91)\end{array}$} & \multirow[b]{2}{*}{ P-value } \\
\hline & $\mathrm{N}$ & $\%$ & $\mathrm{~N}$ & $\%$ & \\
\hline \multicolumn{6}{|l|}{ Gender } \\
\hline Male & 171 & 53.3 & 48 & 52.7 & \multirow[t]{2}{*}{0.9296} \\
\hline Female & 150 & 46.7 & 43 & 47.3 & \\
\hline \multicolumn{6}{|l|}{ Age (years) } \\
\hline$<60$ & 79 & 24.6 & 21 & 23.1 & \multirow[t]{2}{*}{0.7633} \\
\hline$\geq 60$ & 242 & 75.4 & 70 & 76.9 & \\
\hline \multicolumn{6}{|l|}{ Tumor site } \\
\hline Colon & 200 & 62.3 & 49 & 53.8 & \multirow[t]{2}{*}{0.1452} \\
\hline Rectum & 121 & 37.7 & 42 & 46.2 & \\
\hline \multicolumn{6}{|l|}{ Pathological stage } \\
\hline I & 57 & 17.8 & 20 & 22 & \multirow[t]{3}{*}{0.3418} \\
\hline II & 147 & 45.8 & 45 & 49.5 & \\
\hline III & 117 & 36.4 & 26 & 28.6 & \\
\hline \multicolumn{6}{|l|}{ Histology } \\
\hline Adenocarcinoma & 282 & 87.9 & 72 & 79.1 & \multirow[t]{2}{*}{0.0346} \\
\hline Colloid & 39 & 12.1 & 19 & 20.9 & \\
\hline \multicolumn{6}{|l|}{ Bcl-2 } \\
\hline Negative & 168 & 52.3 & 27 & 29.7 & \multirow[t]{3}{*}{0.0456} \\
\hline Positive & 153 & 47.7 & 12 & 13.2 & \\
\hline Missing cases & - & - & 52 & 57.1 & \\
\hline \multicolumn{6}{|l|}{$\beta-\mathrm{M}$} \\
\hline Negative & 29 & 9 & - & - & \multirow[t]{3}{*}{0.4813} \\
\hline Positive & 292 & 91 & 5 & 5.5 & \\
\hline Missing cases & - & - & 86 & 94.5 & \\
\hline \multicolumn{6}{|l|}{$\beta-\mathrm{N}$} \\
\hline Negative & 165 & 51.4 & 4 & 4.4 & \multirow[t]{3}{*}{0.2041} \\
\hline Positive & 156 & 48.6 & 1 & 1.1 & \\
\hline Missing cases & - & - & 86 & 94.5 & \\
\hline \multicolumn{6}{|l|}{$\beta-\mathrm{C}$} \\
\hline Negative & 99 & 30.8 & 5 & 5.5 & \multirow[t]{3}{*}{0.0010} \\
\hline Positive & 222 & 69.2 & - & - & \\
\hline Missing cases & - & - & 86 & 94.5 & \\
\hline \multicolumn{6}{|c|}{ Adjuvant chemotherapy } \\
\hline No & 162 & 50.5 & 53 & 58.2 & \multirow[t]{2}{*}{0.1900} \\
\hline Yes & 159 & 49.5 & 38 & 41.8 & \\
\hline
\end{tabular}

Bcl-2, B-cell lymphoma 2; $\beta$-M, membranous $\beta$-catenin; $\beta$-N, nuclear $\beta$-catenin; $\beta$-C, cytoplasmic $\beta$-catenin; $N$, number.

exhibit significance were progressively removed using a backward stepwise procedure, based on the likelihood ratio test. A probability of 0.05 was used for both removal and re-entry criteria. The presence of heterogeneity of the effect of a single predictor on DFS and OS in the various subgroups of patients was evaluated according to the results of an interaction test. All reported $\mathrm{P}$-values are two-sided and $\mathrm{P}<0.05$ was considered to indicate a statistically significant difference. Statistical analyses were performed by Luca Boni at the Istituto Toscano
Tumouri using SAS System 9.2 (SAS Institute, Inc., Cary, NC, USA).

\section{Results}

Patients. During the study period 412 patients with CRC were enrolled. However, 91 patients were excluded due to absence or incompleteness of follow-up data, and/or the technical impossibility of assessing the biological markers. This 
Table II. Association between the expression of Bcl-2 and nuclear $\beta-\mathrm{N}$, and clinicopathological data.

\begin{tabular}{|c|c|c|c|c|c|c|}
\hline \multirow[b]{2}{*}{ Variable } & \multicolumn{3}{|c|}{$\begin{array}{l}\text { Immunohistochemical expression } \\
\text { of Bcl-2 }\end{array}$} & \multicolumn{3}{|c|}{$\begin{array}{c}\text { Immunohistochemical expression } \\
\text { of } \beta-\mathrm{N}\end{array}$} \\
\hline & Negative (\%) & Positive (\%) & $\mathrm{P}$-value & Negative (\%) & Positive (\%) & P-value \\
\hline All cases & $168(52.3)$ & 153 (47.7) & - & $165(51.4 \%)$ & $156(48.6)$ & - \\
\hline \multicolumn{7}{|l|}{ Gender } \\
\hline Male & $89(52.0)$ & $82(48.0)$ & 0.912 & $87(50.9)$ & $84(49.1)$ & 0.841 \\
\hline Female & $79(52.7)$ & $71(47.3)$ & & $78(52.0)$ & $72(48.0)$ & \\
\hline \multicolumn{7}{|l|}{ Age (years) } \\
\hline$<60$ & $44(55.7)$ & $35(44.3)$ & 0.491 & $40(50.6)$ & $39(49.4)$ & 0.875 \\
\hline$\geq 60$ & $124(51.2)$ & $118(48.8)$ & & $125(51.7)$ & $117(48.3)$ & \\
\hline \multicolumn{7}{|l|}{ Tumor site } \\
\hline Colon & $102(51.0)$ & $98(49.0)$ & 0.538 & $103(51.5)$ & 97 (48.5) & 0.964 \\
\hline Rectum & $66(54.5)$ & $55(45.5)$ & & $62(51.2)$ & $59(48.8)$ & \\
\hline \multicolumn{7}{|l|}{ Pathological stage } \\
\hline I & $22(38.6)$ & $35(61.4)$ & 0.069 & $30(52.6)$ & $27(47.4)$ & 0.766 \\
\hline II & $80(54.4)$ & $67(45.6)$ & & $78(53.1)$ & $69(46.9)$ & \\
\hline III & $66(56.4)$ & $51(43.6)$ & & $57(48.7)$ & $60(51.3)$ & \\
\hline \multicolumn{7}{|l|}{ Histology } \\
\hline Adenocarcinoma & $150(53.2)$ & $132(46.8)$ & 0.41 & $139(49.3)$ & $143(50.7)$ & 0.042 \\
\hline Colloid & $18(46.2)$ & $21(53.8)$ & & $26(66.7)$ & $13(33.3)$ & \\
\hline \multicolumn{7}{|l|}{$\mathrm{Bcl}-2$} \\
\hline Negative & N/A & N/A & N/A & $94(56.0)$ & $74(44.0)$ & 0.087 \\
\hline Positive & & & & $71(46.4)$ & $82(53.6)$ & \\
\hline \multicolumn{7}{|l|}{$\beta-\mathrm{M}$} \\
\hline Negative & $12(41.4)$ & 17 (58.6) & 0.216 & $5(17.2)$ & $24(82.8)$ & $<0.001$ \\
\hline Positive & $156(53.4)$ & $136(46.6)$ & & $160(54.8)$ & $132(45.2)$ & \\
\hline \multicolumn{7}{|l|}{$\beta-\mathrm{N}$} \\
\hline Negative & $94(57.0)$ & $71(43.0)$ & 0.087 & N/A & N/A & N/A \\
\hline Positive & $74(47.4)$ & $82(52.6)$ & & & & \\
\hline \multicolumn{7}{|l|}{$\beta-\mathrm{C}$} \\
\hline Negative & $60(60.6)$ & $39(39.4)$ & 0.048 & $78(78.8)$ & $21(21.2)$ & $<0.001$ \\
\hline Positive & $108(48.6)$ & $114(51.4)$ & & 87 (39.2) & $135(60.8)$ & \\
\hline
\end{tabular}

N/A, not applicable; Bcl-2, B-cell lymphoma $2 ; \beta$-N, $\beta$-catenin; $\beta$-M, membranous $\beta$-catenin; $\beta$-C, cytoplasmic $\beta$-catenin.

resulted in a study group of 321 patients for statistical analysis. No significant differences were observed in the demographic and clinicopathological characteristics of the patients in the study group, compared with the patients in the excluded group (Table I).

Bcl-2 and $\beta$-catenin findings. Positive immunohistochemical staining for Bcl-2 was detected in 153 out of the $321(47.7 \%)$ carcinoma specimens. Nuclear localization of $\beta$-catenin was detected in 156 cases (48.6\%), with cytoplasmic and membrane localisation found in $222(69.2 \%)$ and 292 (91.0\%) cases, respectively. The association between $\mathrm{Bcl}-2$ and $\beta-\mathrm{N}$ expression, and the demographic and clinicopathological variables are presented in Table II. Bcl-2 was expressed more frequently in pathological stage I tumors, compared with stage II or III tumours $(\mathrm{P}=0.069)$. There was also a significant association between $\mathrm{Bcl}-2$ expression and $\beta-\mathrm{C}$ expression $(\mathrm{P}=0.048) . \beta-\mathrm{N}$ expression was more frequently observed in adenocarcinoma samples, compared with colloid carcinoma samples $(50.7 \%$ vs $33.3 \%, \mathrm{P}=0.042$ ). There was a significant association between the absence of $\beta$-M expression and the presence of $\beta$-N expression, with $82.8 \%$ of $\beta$-M-negative tumours (compared with only $45.2 \%$ of $\beta$-M-positive cases) positive for $\beta$-N expression $(\mathrm{P}<0.001)$. Tumours that were positive for $\beta-\mathrm{C}$ expression were frequently also positive for $\beta-\mathrm{N}$ expression $(\mathrm{P}<0.001)$.

Association between pathological and biomolecular variables, and survival. Following surgery, follow-up data was collected from each patient according to the Associazione Italiana di Oncologia Medica guidelines (www.AIOM.it), with a median follow-up time of 5.3 years (IQR=3.0-7.2). Adjuvant chemotherapy, according to international guidelines (14), was 
Table III. Univariate analysis of five-year disease-free survival and overall survival, in patients with CRC.

\begin{tabular}{|c|c|c|c|c|c|c|c|}
\hline \multirow[b]{2}{*}{ Variable } & \multirow[b]{2}{*}{$\mathrm{N}$} & \multicolumn{3}{|c|}{$\begin{array}{l}\text { Disease-free survival } \\
\text { (83 events) }\end{array}$} & \multicolumn{3}{|c|}{$\begin{array}{l}\text { Overall survival } \\
\text { (55 events) }\end{array}$} \\
\hline & & 5 -year \% & $\operatorname{HR}(95 \% \mathrm{CI})$ & P-value & 5 -year \% & HR $(95 \%$ CI) & P-value \\
\hline All cases & 321 & 70 & - & - & 80 & - & - \\
\hline \multicolumn{8}{|l|}{ Gender } \\
\hline Male & 171 & 68 & 1 (ref.) & \multirow[t]{2}{*}{0.472} & 79 & 1 (ref.) & \multirow[t]{2}{*}{0.437} \\
\hline Female & 150 & 73 & $0.85(0.55-1.32)$ & & 81 & $0.81(0.47-1.38)$ & \\
\hline \multicolumn{8}{|l|}{ Age (years) } \\
\hline$<60$ & 79 & 72 & 1 (ref.) & \multirow[t]{2}{*}{0.993} & 83 & 1 (ref.) & \multirow[t]{2}{*}{0.436} \\
\hline$\geq 60$ & 242 & 70 & $1.00(0.60-1.65)$ & & 79 & $1.30(0.67-2.52)$ & \\
\hline \multicolumn{8}{|l|}{ Tumor site } \\
\hline Colon & 200 & 71 & 1 (ref.) & \multirow[t]{2}{*}{0.401} & 81 & 1 (ref.) & \multirow[t]{2}{*}{0.127} \\
\hline Rectum & 121 & 70 & $1.21(0.78-1.87)$ & & 78 & $1.51(0.89-2.56)$ & \\
\hline \multicolumn{8}{|l|}{ Pathological stage } \\
\hline I & 57 & 87 & 1 (ref.) & \multirow[t]{3}{*}{$<0.001$} & 93 & 1 (ref.) & \multirow[t]{3}{*}{$<0.001$} \\
\hline II & 147 & 74 & $1.82(0.80-4.14)$ & & 84 & $1.51(0.56-4.08)$ & \\
\hline III & 117 & 58 & $4.12(1.86-9.14)$ & & 68 & $3.92(1.53-10.1)$ & \\
\hline \multicolumn{8}{|l|}{ Histology } \\
\hline Adenocarcinoma & 282 & 72 & 1 (ref.) & \multirow[t]{2}{*}{0.058} & 81 & 1 (ref.) & \multirow{2}{*}{0.047} \\
\hline Colloid & 39 & 60 & $1.73(0.97-3.08)$ & & 70 & $1.98(1.00-3.93)$ & \\
\hline \multicolumn{8}{|l|}{ Bcl-2 } \\
\hline Negative & 168 & 66 & 1 (ref.) & \multirow[t]{2}{*}{0.254} & 78 & 1 (ref.) & \multirow[t]{2}{*}{0.603} \\
\hline Positive & 153 & 75 & $0.78(0.50-1.20)$ & & 82 & $0.87(0.51-1.48)$ & \\
\hline \multicolumn{8}{|l|}{$\beta-\mathrm{M}$} \\
\hline Negative & 29 & 75 & 1 (ref.) & \multirow[t]{2}{*}{0.986} & 77 & 1 (ref.) & \multirow[t]{2}{*}{0.483} \\
\hline Positive & 292 & 70 & $1.01(0.49-2.09)$ & & 80 & $0.75(0.34-1.67)$ & \\
\hline \multicolumn{8}{|l|}{$\beta-\mathrm{N}$} \\
\hline Negative & 165 & 70 & 1 (ref.) & \multirow[t]{2}{*}{0.69} & 80 & 1 (ref.) & \multirow[t]{2}{*}{0.936} \\
\hline Positive & 156 & 71 & $0.92(0.60-1.41)$ & & 80 & $1.02(0.60-1.74)$ & \\
\hline$\beta-C$ & & & & & & & \\
\hline Negative & 99 & 72 & 1 (ref.) & 0.303 & 80 & 1 (ref.) & 0.796 \\
\hline Positive & 222 & 69 & $1.31(0.78-2.19)$ & & 80 & $1.09(0.58-2.03)$ & \\
\hline Adjuvant chemothe & & & & & & & \\
\hline No & 162 & 74 & 1 (ref.) & 0.048 & 83 & 1 (ref.) & 0.187 \\
\hline Yes & 159 & 67 & $1.55(1.00-2.39)$ & & 76 & $1.43(0.84-2.44)$ & \\
\hline
\end{tabular}

CRC, colorectal cancer; $\beta$-M, membranous $\beta$-catenin; $\beta$-C, cytoplasmic $\beta$-catenin; CI, confidence interval; HR, hazard ratio; (ref.), reference group.

administered to 2 out of 57 (3.5\%), 55 out of $147(37.4 \%)$ and 102 out of $117(87.2 \%)$ patients with pathological stage I, II and III CRC, respectively. Five-year DFS and OS were 70 and $80 \%$, respectively, in the whole group of 321 patients.

The univariate analysis determined the associations between DFS and OS outcome variables, and demographic and clinicopathological characteristics (Table III). Pathological stage was the only variable that significantly affected both DFS and OS, with a progressively increasing risk of recurrence or death from pathological stage I to stage III $(\mathrm{P}<0.001)$. Furthermore, patients with colloid carcinoma had a slightly increased risk of recurrence $(\mathrm{P}=0.058)$ and death $(\mathrm{P}=0.047)$, compared with patients with adenocarcinoma.

A similar, although less evident trend was observed in the patients who underwent adjuvant chemotherapy, compared with untreated patients $(\mathrm{P}=0.048$ and $\mathrm{P}=0.187$ for DFS and $\mathrm{OS}$, respectively). These results suggest that neither of the prospective biomarkers, including the various cellular localisations of $\beta$-catenin, was capable of distinguishing patients with a high risk of recurrence or death, from those with a better prognosis.

Multivariate analysis confirmed that pathological stage remained the only accurate predictor of locoregional and/or 
Table IV. Effects of nuclear $\beta$-catenin ( $\beta-\mathrm{N})$ expression and adjuvant chemotherapy on five-year disease-free survival and overall survival in various subgroups of patients with CRC.

A, Effect of $\beta$-N positivity vs. negativity according to pathological stage (321 cases) ${ }^{\mathrm{b}}$

\begin{tabular}{|c|c|c|c|c|}
\hline \multirow[b]{2}{*}{ Variable } & \multicolumn{2}{|c|}{ Disease-free survival } & \multicolumn{2}{|c|}{ Overall survival } \\
\hline & $\operatorname{HR}(95 \% \mathrm{CI})$ & P-value ${ }^{a}$ & HR (95\% CI) & P-value ${ }^{a}$ \\
\hline & 83 events & & 55 events & \\
\hline Stage I & $2.65(0.51-13.6)$ & 0.050 & $1.47(0.25-8.82)$ & 0.094 \\
\hline Stage II & $1.26(0.62-2.56)$ & & $1.99(0.75-5.32)$ & \\
\hline Stage III & $0.50(0.28-0.91)$ & & $0.55(0.27-1.10)$ & \\
\hline
\end{tabular}

B, Effect of adjuvant chemotherapy vs. no treatment according to $\beta-\mathrm{N}$ expression (147 pathological stage II cases)

\begin{tabular}{|c|c|c|c|c|}
\hline \multirow[b]{2}{*}{ Variable } & \multicolumn{2}{|c|}{ Disease-free survival } & \multicolumn{2}{|c|}{ Overall survival } \\
\hline & HR (95\% CI) & P-value ${ }^{a}$ & HR (95\% CI) & P-value ${ }^{a}$ \\
\hline & 31 events & & 23 events & \\
\hline Negative & $1.01(0.35-2.92)$ & 0.573 & $0.62(0.11-3.41)$ & 0.913 \\
\hline Positive & $0.65(0.21-1.99)$ & & $0.70(0.19-2.60)$ & \\
\hline
\end{tabular}

atest for interaction; 'bazard ratio (HR) estimates adjusted for adjuvant chemotherapy. CI, confidence interval; $\beta$-N, $\beta$-catenin .

distant recurrence $(\mathrm{P}<0.001)$, with an increasing risk of recurrence in patients with pathological stage II $(\mathrm{HR}=2.04,95 \% \mathrm{CI}$ 0.87-4.81) and III (HR=5.56, 95\% CI 2.14-14.45), compared with patients with stage I disease. The effect of stage on OS was $(\mathrm{P}<0.001)$ similar for the HR, which was $1.87(95 \% \mathrm{CI}$ $0.66-5.29)$ and 5.76 (95\% CI 1.87-17.67) in stage II vs I, and stage III vs I comparisons, respectively.

The association between $\beta-\mathrm{N}$ expression and pathological stage is shown in Table IV. The prognostic impact of $\beta-\mathrm{N}$ positivity on DFS, adjusted for adjuvant chemotherapy administration, was heterogeneous in the three stages $(\mathrm{P}=0.050)$. In stage I cases, the risk of recurrence in patients with $\beta-\mathrm{N}$ positive tumours was more than double that of patients with $\beta-\mathrm{N}$ negative tumours. In stage II cases, there was only a slight increase in the HR for patients with $\beta$-N positive tumors compared with $\beta$-N negative tumours. By contrast, for patients with stage III disease, a marked reduction in the HR was observed in those with $\beta-\mathrm{N}$ positive tumors compared with those with $\beta-\mathrm{N}$ negative tumours. A similar heterogeneity of the effect of $\beta-\mathrm{N}$ on OS was also observed. However, these findings were not statistically significant.

The interaction between treatment with chemotherapy and $\beta-\mathrm{N}$ expression in patients with pathological stage II CRC is shown in Table IV. In this subgroup, the increased DFS in the patients undergoing adjuvant chemotherapy appeared to be associated, although not significantly, with $\beta-\mathrm{N}$ positivity (HR: 0.65; 95\% CI 0.21-1.99).

\section{Discussion}

The results of the present study indicate that there is heterogeneity in terms of the prognostic impact of $\beta-\mathrm{N}$ expression in the various stages of operable CRC. An increased risk of recurrence and death was observed in $\beta-\mathrm{N}$ positive cases for patients with stage I and II disease, whereas a reduced risk was observed in those with stage III disease. However, no potential reliable prognostic role for $\mathrm{Bcl}-2$ and $\beta$-catenin expression was demonstrated. Conversely, the pathological stage of disease was confirmed as an independent prognostic factor.

The present study was designed based upon the previous experience of this group in evaluating the prognostic role of potential biomarkers in breast, larynx and urinary bladder cancers (15-25). The current study aimed to identify novel biomarkers with a possible prognostic role in operable CRC. Therefore, patients with stage IV disease were excluded, in order to avoid the confounding effects of the aggressive behaviour of these tumours, and of the heterogeneous presentation and treatment strategies that are specific to patients with metastatic disease.

Positive immunostaining for Bcl-2 was observed in $47.7 \%$ of tumours, with a higher frequency in patients with pathological stage I compared with stage II or III patients. This finding was not statistically significant, although it was concordant with results from previous reports $(26,27)$. Furthermore, the lack of prognostic significance of Bcl-2 in the present study is also in accordance with the results of previous studies $(28,29)$. However, a number of other studies have reported Bcl-2 expression to be a favorable prognostic factor $(26,27)$.

$\beta$-catenin membrane positivity was detected in $91.0 \%$ of tissue specimens, whereas cytoplasmic and nuclear staining were less frequently observed $(69.2 \%$ and $48.6 \%$, respectively). Comparisons between the three cellular localisations of $\beta$-catenin demonstrated that $\beta$-M negativity was more frequently associated with localisation to the nucleus 
(82.8\%), and that $\beta-\mathrm{C}$ and $\beta-\mathrm{N}$ were frequently co-expressed or not expressed at all. This pattern of expression confirms a previously reported association between the integrity of the APC-complex and the normal turnover of $\beta$-catenin (30).

The present study provided no evidence to suggest an association between $\beta$-catenin positivity/negativity, and DFS and OS in CRC. Conversely, previous reports have suggested a favorable and unfavorable prognostic role for $\beta-\mathrm{M}$ and $\beta-\mathrm{N}$ expression, respectively (31-39). However, a notable finding from the present study was the differential prognosis associated with $\beta-\mathrm{N}$ expression at particular pathological stages of disease, on DFS and OS. In stage I disease, positive $\beta-\mathrm{N}$ expression was shown to be associated with an increased risk of recurrence and death. A similar association was observed, although the results were not statistically significant, in patients with stage II. By contrast, in stage III CRC, $\beta-\mathrm{N}$ positivity was associated with a better prognosis. The data were adjusted for adjuvant chemotherapy, as the proportion of patients receiving this treatment was different in all three stages. These results may be partly attributable to an increased sensitivity of $\beta-\mathrm{N}$ positive tumours to chemotherapy. This hypothesis is supported by the previous demonstration of the participation of $\beta-\mathrm{N}$ in activating the transcription of genes involved in proliferation $(10,40)$. The present results suggest that more rapidly proliferating tumors are associated with a worse prognosis, but may also represent a more favorable target for adjuvant chemotherapy (41). $\beta$ - $\mathrm{N}$ expression may therefore be a more reliable indicator of potential proliferation, and consequently of disease aggressiveness, compared with other markers, such as Ki-67, as it does not appear to be influenced by tumour microenviromental factors as it function at a gene transcriptional level.

In order to verify this hypothesis and to improve understanding regarding the predictive role of $\beta-\mathrm{N}$ in the prognosis of CRC, the effects of chemotherapy on DFS and OS, in relation to $\beta-\mathrm{N}$ status, were studied in patients with stage II disease. Stage II CRC was the only stage that allowed for such a statistical analysis, due to the fact that there were approximately equal numbers of patients who did or did not receive adjuvant chemotherapy. A more beneficial effect (risk of relapse) of adjuvant therapy on DFS was associated with $\beta$-N expression, although this finding was not statistically significant. A similar effect was not observed for OS. This discrepancy may be due to the compensatory effect of chemotherapy on OS, which was started in the majority of cases following recurrence.

The results of the present study suggest that the expression of $\beta-\mathrm{N}$ in cancer cells may be a potential novel marker of a more favourable response to chemotherapy. However, due to the small number of observed events in the present study this finding should be interpreted with caution, and requires further investigation.

In conclusion, the present study indicates that pathological stage is the only independent variable that predicts DFS and OS in non-metastatic operable CRC. Neither of the biomarkers studied had a similar prognostic value. Furthermore, although these data require confirmation, the heterogeneity of the prognostic impact of nuclear $\beta$-catenin in the different stages may suggest a possible role in predicting the response of a tumour to chemotherapy.

\section{Acknowledgements}

The present study was made possible by the will, continued engagement and support of Professor Aldo Becciolini, Head of the Laboratory of Cell Biology and Radiation Biology of the University of Florence.

\section{References}

1. von Karsa L, Anttila A, Ronco G, Ponti A, Malila N, Arbyn M, et al: Cancer screening in the European Union- Report on the implementation of the Council Recommendation on cancer screening. First Report. International Agency for Research on Cancer, European Communities 2008.

2. Ferlay J, Shin HR, Bray F, Forman D, Mathers C and Parkin DM: GLOBOCAN 2008 v2.0, Cancer Incidence and Mortality Worldwide: IARC CancerBase No. 10 (Internet). Lyon, France: International Agency for Research on Cancer. Available from: http://globocan.iarc.fr

3. Zhou Z, Wu X, Wang R, Li L, Lu Z, Chen G, et al: Optimal use of adjuvant chemotherapy in stage II colorectal cancer. Int J Colorectal Dis 26: 867-873, 2011.

4. QUASAR Collaborative Group, Gray R, Barnwell J, McConkey C, Hills RK, Williams NS and Kerr DJ: Adjuvant chemotherapy versus observation in patients with colorectal cancer: a randomised study. Lancet 370: 2020-2029, 2007.

5. Quah HM, Chou JF, Gonen M, Shia J, Schrag D, Landmann RG, et al: Identification of patients with high-risk stage II colon cancer for adjuvant therapy. Dis Colon Rectum 51: 503-507, 2008.

6. Gertler R, Rosenberg R, Schuster T and Friess H: Defining a high-risk subgroup with colon cancer stages I and II for possible adjuvant therapy. Eur J Cancer 45: 2992-2999, 2009.

7. Fearon ER and Vogelstein B: A genetic model for colorectal tumourigenesis. Cell 61: 759-767, 1990.

8. Strasser A, Huang DC and Vaux DL: The role of the bcl-2/ced-9 gene family in cancer and general implications of defects in cell death control for tumourigenesis and resistance to chemotherapy. Biochim Biophys Acta 1333: 151-178, 1997.

9. Armaghany T, Wilson JD and Mills G: Genetic alterations in colorectal cancer. Gastrointest Cancer Res 5: 19-27, 2012.

10. Fodde R and Tomlinson I: Nuclear beta-catenin expression and Wnt signalling: in defence of the dogma. J Pathol 221: 239-241, 2010.

11. Wang $Z$ and Ma Q: Beta-catenin is a promising key factor in the SDF-1/CXCR4 axis on metastasis of pancreatic cancer. Med Hypotheses 69: 816-820, 2007.

12. Edge SB, Byrd DR, Compton CC, Fritz AG, Greene FL and Trotti A (eds): AJCC Cancer Staging Manual and Handbook. 7th edition. Springer, New York, 2010.

13. Schemper M and Smith TL: A note on quantifying follow-up in studies of failure time. Control Clin Trials 17: 343-346, 1996.

14. Labianca R, Nordlinger B, Beretta GD, Mosconi S, Mandalà M, Cervantes A and Arnold D; ESMO Guidelines Working Group: Early colon cancer: ESMO Clinical Practice Guidelines for diagnosis, treatment and follow-up. Ann Oncol 24 (Suppl 6): 64-72, 2013.

15. Becciolini A, Porciani S, Balzi M,Lanini A, Scubla E, Pacini P, et al: Cell kinetics and biochemical parameters in breast cancer. Int J Biol Markers 7: 16-20, 1992.

16. Becciolini A, Balzi M, Boanini P, Maugeri A, Pacini P, Bianchi S, et al: Cell kinetics in breast cancer. In Vivo 7: 627-629, 1993.

17. Medri L, Nanni O, Volpi A, Scarpi E, Dubini A, Riccobon A, et al: Angiogenesis in breast cancer. Eur J Oncol 7: 185-189, 2002.

18. Watson AJ, Merritt AJ, Jones LS, Askew JN, Anderson E, Becciolini A, et al: Evidence for reciprocity of bcl-2 and p53 expression in human colorectal adenomas and carcinomas. Br J Cancer 73: 889-895, 1996.

19. Becciolini A, Balzi M, Faraoni P, Tisti E, Zappoli Thyrion G, Giachè $\mathrm{V}$, et al: Colonic cell proliferation in normal mucosa of patients with colon cancer. Acta Oncol 37: 65-71, 1998.

20. Cianchi F, Balzi M, Becciolini A, Giachè V, Messerini L, Palomba A, et al: Correlation between DNA content and p53 deletion in colorectal cancer. Eur J Surg 165: 363-368, 1999.

21. Wilson JW, Nostro MC, Balzi M, Faraoni P, Cianchi F, Becciolini A, et al: Bcl-w expression in colorectal adenocarcinoma. Br J Cancer 82: 178-185, 2000. 
22. Wilson JW, Deed RW, Inoue T, Balzi M, Becciolini A, Faraoni $\mathrm{P}$, et al: Expression of Id helix-loop-helix proteins in colorectal adenocarcinoma correlates with p53 expression and mitotic index. Cancer Res 61: 8803-8810, 2001

23. Volpi A, De Paola F, Nanni O, Granato AM, Bajorko P, Becciolini A, et al: Prognostic significance of biological markers in node-negative breast cancer patients: a prospective study. Breast Cancer Res Treat 63: 181-192, 2000.

24. Balzi M, Ninu MB, Becciolini A, Scubla E, Boanini P Gallina E, et al: Labeling index in squamous cell carcinoma of the larynx. Head Neck 13: 344-348, 1991.

25. Muraro GB, Melone F, Farina U, Balzi M and Becciolini A: Adjuvant therapy with BCG in superficial bladder cancer selected by proliferative activity assessment. J Chemother 8S4: 328-330, 1996

26. Zhao DP, Ding XW, Peng JP, Zheng YX and Zhang SZ: Prognostic significance of bcl-2 and p53 expression in colorectal carcinoma. J Zhejiang Univ Sci B 6: 1163-1169, 2005.

27. Manne U, Myers RB, Moron C, Poczatek RB, Dillard S, Weiss $\mathrm{H}$, et al: Prognostic significance of $\mathrm{Bcl}-2$ expression and p53 nuclear accumulation in colorectal adenocarcinoma. Int J Cancer 74: 346-358, 1997.

28. Bosari S, Moneghini L, Graziani D, Lee AK, Murray JJ, Coggi G, et al: bcl-2 oncoprotein in colorectal hyperplastic polyps, adenomas, and adenocarcinomas. Hum Pathol 26: 534-540, 1995

29. Menezes HL, Jucá MJ, Gomes EG, Nunes BL, Costa HO and Matos D: Analysis of the immunohistochemical expressions of p53, bcl-2 and $\mathrm{Ki}-67$ in colorectal adenocarcinoma and their correlations with the prognostic factors. Arq Gastroenterol 47: 141-147, 2010 (In Portuguese).

30. Markowitz SD and Bertagnolli MM: Molecular origins of cancer: Molecular basis of colorectal cancer. N Engl J Med 361: 2449-2460, 2009

31. Hugh TJ, Dillon SA, Taylor BA, Pignatelli M, Poston GJ and Kinsella AR: Cadherin-catenin expression in primary colorectal cancer: a survival analysis. Br J Cancer 80: 1046-1051, 1999.
32. Pancione M, Forte N, Sabatino L, Tomaselli E, Parente D, Febbraro A, et al: Reduced beta-catenin and peroxisome proliferator-activated receptor-gamma expression levels are associated with colorectal cancer metastatic progression: correlation with tumour-associated macrophages, cyclooxygenase 2 and patient outcome. Hum Pathol 40: 714-725, 2009.

33. Wong SC, Lo ES, Chan AK, Lee KC and Hsiao WL: Nuclear beta-catenin as a potential prognostic and diagnostic marker in patients with colorectal cancer from Hong Kong. Mol Pathol 56: 347-352, 2003.

34. Wong SC, Lo ES, Chan JK and Hsiao WL: Prognostic and diagnostic significance of beta-catenin nuclear immunostaining in colorectal cancer. Clin Cancer Res 10: 1401-1408, 2004.

35. Tatsuguchi A, Kishida T, Fujimori S, Tanaka S, Gudis K, Shinji S, et al: Differential expression of cyclo-oxygenase- 2 and nuclear $\beta$-catenin in colorectal cancer tissue. Aliment Pharmacol Ther 24 (Suppl. 4): 153-159, 2006.

36. Matsuoka T, Mitomi H, Fukui N, Kanazawa H, Saito T, Hayashi T, et al: Cluster analysis of claudin-1 and -4, E-cadherin, and $\beta$-catenin expression in colorectal cancers. J Surg Oncol 103: 674-686, 2011.

37. Ikeguchi M, Makino $M$ and Kaibara N: Clinical significance of E-cadherin-catenin complex expression in metastatic foci of colorectal carcinoma. J Surg Oncol 77: 201-207, 2001.

38. Günther K, Brabletz T, Kraus C, Dworak O, Reymond MA, Jung A, et al: Predictive value of nuclear beta-catenin expression for the occurrence of distant metastases in rectal cancer. Dis Colon Rectum 41: 1256-1261, 1998.

39. Chung GG, Provost E, Kielhorn EP, Charette LA, Smith BL and Rimm DL: Tissue microarray analysis of beta-catenin in colorectal cancer shows nuclear phospho-beta-catenin is associated with a better prognosis. Clin Cancer Res 7: 4013-4020, 2001.

40. Zeilstra J, Joosten SPJ, Wensveen FM, Dessing MC, Schütze DM, Eldering E, et al: WNT signaling controls expression of pro-apoptotic BOK and BAX in intestinal cancer. Biochem Biophys Res Commun 406: 1-6, 2011.

41. Bonadonna G, Robustelli Della Cuna G and Valagussa P: Medicina Oncologica. Milano: Elsevier; 2007. 